\title{
Aerosol Impacts on Meteorological Elements and Surface Energy Budget over an Urban Cluster Region in the Yangtze River Delta
}

\author{
Xiaolu Ling ${ }^{1,2 *}$, Xiaomen Han ${ }^{1}$ \\ ${ }^{1}$ Institute for Climate and Global Change Research, School of Atmospheric Sciences, Nanjing University, Nanjing 210023, \\ China \\ ${ }^{2}$ Joint International Research Laboratory of Atmospheric and Earth System Sciences, School of Atmospheric Sciences, \\ Nanjing University, Nanjing 210023, China
}

\begin{abstract}
The Yangtze River Delta (YRD) is a typical example of regions that are dramatically influenced by both human activity and a monsoonal climate. Data on the near-surface micro-meteorology, radiation, and energy fluxes were collected and analyzed at the Lishui field observation site in the suburb of Nanjing to investigate aerosol impacts on the radiation budget and land surface-atmosphere heat, water, and mass exchanges. Cluster analysis, composite analysis, and case study were applied to selected typical polluted/non-polluted days. The results indicate that the mean daily surface pressure is $6.6 \mathrm{hPa}$ lower on polluted than non-polluted days in Nanjing. Northeasterly winds often prevail on the polluted days, with wind speeds being $60 \%$ lower than on non-polluted days. Aerosols directly reduce the net radiation flux at the surface, with a maximum reduction of $180 \mathrm{~W} \mathrm{~m}^{-2}$. During the early stage of air pollution events, the surface pressure is lower, and wind speeds rapidly decrease, whereas during the peak of pollution, low surface pressure and wind speeds linger, effectively preventing the dispersion of air pollutants. Meanwhile, the temperature often decreases, and the relative humidity subsequently increases. As the wind speed and surface pressure increase, the AQI gradually decreases, and the air pollution event ends.
\end{abstract}

Keywords: Urban cluster region; Meteorological elements; Surface energy budget.

\section{INTRODUCTION}

Atmospheric aerosols refer to a mixture of multi-phase solid and liquid particles with a diameter of $0.001-100 \mu \mathrm{m}$ suspended in the atmosphere. In addition to natural background aerosols (dust, sea salt, biogenic emissions, volcanic eruptions, etc.), anthropogenic aerosols and pollutant emissions have been increasing with rapid economic development and intensified human activities such as urbanization, transportation, fossil fuel combustion, and industrial and agricultural processes (Guo et al., 2011; Li et al., 2017). Toxic fine airborne particles can damage human health. Previous studies have shown that a high $\mathrm{PM}_{2.5}$ concentration has significant impacts on the development of childhood lung function. In detail, for every $10 \mu \mathrm{g} \mathrm{m}^{-3}$ increase in $\mathrm{PM}_{2.5}$ the risk of lung cancer and heart disease increases by $6-8 \%$, reducing the life expectancy of people in North China by an average of 5.5 years (Chen et al., 2013b).

\footnotetext{
${ }^{*}$ Corresponding author.

Tel.: +86 25 89681619; Fax: +86 2589681619

E-mail address: lingxl@nju.edu.cn
}

Due to the well-known radiative and microphysical effects of aerosols particles, the study of aerosol impacts on weather and climate has become a cutting-edge topic in atmospheric science, oceanography and environmental studies.

Aerosols can affect global and regional climate via the following processes: (1) Aerosol radiative effects reduce incoming solar radiation, change the radiative heating distribution in the atmosphere, and directly affect radiative forcing via dissipation and absorption of solar radiation (Miller and Tegen, 1998; Han et al., 2013; Huang et al., 2015); (2) as cloud condensation and ice nuclei, aerosols affect cloud physics and cloud duration, and aerosol in turn delays the precipitation (indirect effect; Twomey, 1974; Fan et al., 2008; Guo et al., 2016a; Lee et al., 2016; Xu et al., 2018); and (3) aerosol radiative effects can heat air masses, leading to cloud drop evaporation and thus affecting cloud numbers and albedo (semi-direct effect; Koren et al., 2004; Huang et al., 2006; Helmert et al., 2007; Koch and Del Genio, 2010). Interaction between aerosols and the atmosphere is quite complicated because of the different physical-chemical properties of various types of aerosols, thus large uncertainties still exist in the study of aerosol impacts on global climate and climate change (Parajuli et 
al., 2013; Wang et al., 2014). The IPCC (2013) noted that direct radiative forcing by aerosols is $-0.4 \mathrm{~W} \mathrm{~m}^{-2}$ (approximately from -0.2 to $-0.6 \mathrm{~W} \mathrm{~m}^{-2}$ ) globally, among which the global average radiative forcing is $0.2 \mathrm{~W} \mathrm{~m}^{-2}$ (0.05 to $0.35 \mathrm{~W} \mathrm{~m}^{-2}$ ) by black carbon and $-0.05 \mathrm{~W} \mathrm{~m}^{-2}$ by organic carbon aerosols. Uncertainties in the climatic effects of aerosols are largely related to uncertainties in the spatial and temporal distributions of aerosols and an incomplete understanding of the aerosol-climate feedback.

The Yangtze River Delta (YRD) is a major region in China that has undergone rapid economic development and dramatic human activities accompanied by significant energy and resources consumption, resulting in various air pollutants emitted into the atmosphere. Fine particles from dust events and biomass burning (via long-distance transport) that have strong extinction effects on radiation also affect this region. As a result, air pollution in this region presents special regional characteristics of high complexity. Globally, eastern China, the northern Indian Peninsula and southern Himalayas, and south-central Sahara in Africa are the major regions with severe and continuous aerosol pollution, where the average aerosol optical thickness (AOD) can reach approximately 0.8 (Chen et al., 2013b; Liu et al., 2018). Areas with AOD greater than 1.0 have been increasing most rapidly during recent years, and the increasing rate is much higher in urban clusters on flat plains than those in mountainous regions (Tegen et al., 2000; Luo et al., 2001; Li et al., 2003; Tegen et al., 2009; Rasheed et al., 2015). Human activities are the major source of aerosols in eastern China, and sulfate emissions in economically developed eastern China account for $97.7 \%$ of China's total emission (Ren et al., 2012). Under certain meteorological conditions, anthropogenic aerosols can rapidly accumulate on the YRD and influence the formation of local secondary pollution via heterogeneous reactions with dust and aerosols produced by biomass burning (Nie et al., 2015). Therefore, it is necessary to investigate in detail the radiative effects of aerosols on the YRD.

The increase in aerosol concentration is related to air pollution and is the primary reason for the reduction of net shortwave radiation in eastern China. Observations at weather stations indicate that the total surface radiation at most of the stations has decreased by more than $6 \%$ per decade, and the largest decrease has occurred on the YRD, where human activities are the most intense (Zhang et al., 2004; Che et al., 2005; Richter et al., 2005; Qian et al., 2006, 2007, 2011). Xia et al. (2007) analyzed the aerosol optical properties and radiative effects on the YRD based on data from 2005-2006 collected at the Taihu Station in the EAST-AIRE field experiment. They found that a high concentration of aerosols reduced the direct radiation by $112.6 \mathrm{~W} \mathrm{~m}^{-2}$ and increased the diffusive shortwave radiation by $67.1 \mathrm{~W} \mathrm{~m}^{-2}$ respectively, which finally reduced the total shortwave radiation by $45.5 \mathrm{~W} \mathrm{~m}^{-2}$. Wang and Shi (2002) investigated the impact of changes in cloud and surface albedo on direct radiative effects of aerosols, and found that a higher surface albedo reduces the sulfate radiative effects of direct radiation, and vice versa. Furthermore, the impact of sulfates on the surface radiation balance is equivalent to that of the atmosphere. Aerosol effects have led to a decrease in the surface temperature in mainland China, with large decreases of $-0.4^{\circ} \mathrm{C}$ and $-0.5^{\circ} \mathrm{C}$ from the Sichuan Basin to the middle and lower reaches of the Yangtze River and from the northern Tibetan Plateau to the Ordos Loop region, respectively. The spatial and temporal distribution of aerosols is undoubtedly affected by the East Asian monsoon, that is, aerosol effects can reduce the surface temperature and precipitation during the summer, leading to a weakened summer monsoon in East (or South) Asia (Liu et al., 2009; Zhang et al., 2012; Jin et al., 2014; Huang et al., 2016). While the main causes induced by aerosol for the weakening summer monsoon at least include the reduced land-sea thermal contrast $(\mathrm{Li}$ et al., 2016; Yang et al., 2017). In addition, Xu (2001) proposed that the "south flood-north drought" phenomenon that continuously occurred during the late 1990s in China can be attributed to the southward shift of the rain belt, which was induced by the radiative effect of anthropogenic sulfate aerosols. Fine particles can weaken the urban heat island (UHI) intensities by reducing urban warming during the day (Wu et al., 2017; Li et al., 2018). Studies also found that stronger UHI intensity can drive a strong PBL circulation cell, which redistribute and transport more pollutants far from the emission center (Li et al., 2015). Interaction and feedback between the surface and atmosphere on the YRD is significant with large impacts on water, energy, and momentum exchanges, which makes it important to further study the aerosol impacts on meteorological elements and the surface energy budget (Ding et al., 2013; Cai et al., 2018).

Most previous studies on long-term climatic impacts and short-term meteorological changes by aerosols have been conducted (e.g., Ling et al., 2014; Zhang et al., 2014; Yang et al., 2016), especially over eastern China (Zhuang et al., 2014, 2016, 2017; Shen et al., 2018) and southern China (Zhou et al., 2016). The urban cluster in the Nanjing area was taken as an example in the present study to investigate aerosol impacts on weather and climate in this study. Various regional air pollutant concentration, micro-meteorology and surface radiation budget, and sensible and latent heat flux data were collected and classified based on daily weather conditions. Variations in near-surface meteorological elements, surface energy balance and radiation budget were analyzed. The aim of the present study was to quantitatively evaluate radiative forcing and climatic impacts of air pollution in the region and provide a scientific basis and theoretical support for the development of aerosol radiative modules in climatic models.

\section{DATA AND METHODOLOGY}

\section{Data}

The air quality data were assessed from the daily air quality index (AQI) and $\mathrm{PM}_{2.5}$ concentration issued by the Nanjing Environmental Monitoring Station and Nanjing Meteorological Bureau. AQI is a dimensionless index for quantitative description of air quality condition, which comprehensively consider the contribution of sulfur 
dioxide (SO), nitrogen dioxide (NO), $\mathrm{PM}_{10}, \mathrm{PM}_{2.5}$, carbon monoxide $(\mathrm{CO})$, ozone $\left(\mathrm{O}_{3}\right)$ and other pollutants. The comparison between $\mathrm{AQI}$ and $\mathrm{PM}_{2.5}$ can be used to analyze the contribution of particles, and other pollutants.

In order to consider the contribution of absorbing aerosols, the OMAERUV remote sensing data products were analyzed. The daily ultraviolet aerosol index (UVAI) is derived from the Ozone Monitoring Instrument (OMI) of the Earth Observing System (EOS) AURA satellite launched in July 2004 (Ahmad et al., 2003; Peter et al., 2017). The space resolution is $1^{\circ} \times 1^{\circ}$, and we consider the value from the product grid that is the nearest to the Lishui Station as the aerosol index for absorbing aerosols.

Meteorological elements and radiation were extracted from daily observations collected at Lishui Station in suburban Nanjing (Guo et al., 2014b). Observations at this station have been applied for comparative studies of longterm surface-atmosphere interaction in this region. Lishui
Station $\left(31^{\circ} 43^{\prime} \mathrm{N}, 118^{\circ} 58^{\prime} \mathrm{E}\right)$ is a satellite station of SORPES-NJU in southern Nanjing with two sites: farmland (LS-crop) and grassland (LS-grass), respectively. Fig. 1 shows the locations in Nanjing, surface conditions for LS-crop and LS-grass, and instruments for the different observed variables. The grassland site was used for observations from January 2012 to February 2014, and the surface was largely covered by grass with a height of approximately $60 \mathrm{~cm}$. There is no large-scale surface emission source in the surrounding area. The cropland site was used from January 2013 to February 2014. Winter wheat grows during the winter half-year (from the middle of November to early June) and rice grows from the middle of June to early November in this region. Note that the distance between the cropland and grassland sites was $1.62 \mathrm{~km}$ and their altitudes were nearly the same, thus the two sites were similarly representative of the region for air quality studies.

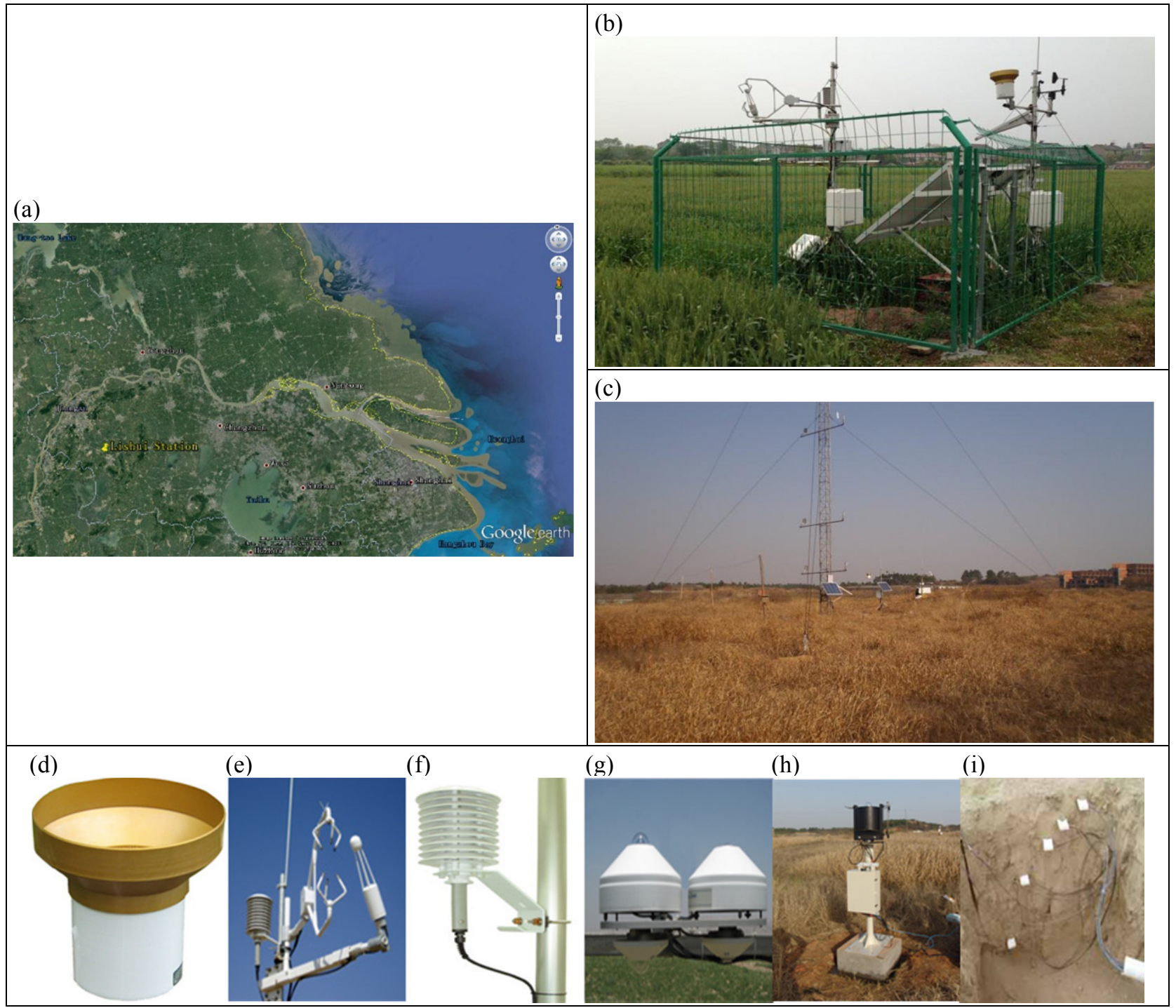

Fig. 1. Location of (a) Lishui Station; surface condition at the (b) crop station (LS-crop) and (c) grass station (LS-grass); and instruments for (d) precipitation, (e-f) surface flux monitoring, (g) surface radiation monitoring, and (h-i) soil parameter monitoring. 
The near surface micro-meteorological elements included temperature $(\mathrm{Ta})$, pressure $(\mathrm{P})$, relative humidity $(\mathrm{RH})$, wind speed $(\mathrm{Ws})$, and wind direction $(\mathrm{Wd})$ at intervals of $30 \mathrm{~min}$. Near surface radiation elements included upward and downward solar radiation and longwave radiation. Momentum and heat fluxes were derived from observations of an eddy covariance (EC) system with a sampling frequency of $10 \mathrm{~Hz}$. A strict data quality control procedure was applied to the observations and the final data products used for the present study were flux data at 30-min intervals (see Table 1). Weather conditions were obtained from the weather website (http://lishi.tianqi.com/).

\section{Methodology}

Cluster analysis, composite analysis and typical case analysis were used in the present study. For the cluster analysis, representative pollution events were selected based on $\mathrm{PM}_{2.5}$ concentration, $\mathrm{AQI}$ and weather condition. Typical polluted days and non-polluted days were selected. Meteorological elements and energy budgets under different aerosol conditions were arithmetically averaged to remove the influences of background weather conditions. Diurnal variations in micro-meteorological elements and radiation fluxes were analyzed and compared under different aerosol distributions. To further analyze the evolution of the aforementioned elements and momentum fluxes during the pollution process, a typical pollution event that occurred from November 28 to December 12 during 2013 was selected to study the characteristic variations in the micrometeorological elements and radiation budget.

\section{Classification of Weather Conditions}

Fig. 2 shows the daily $\mathrm{PM}_{2.5}$ concentration, AQI, and UVAI during the period October 1-December 31, 2013. $\mathrm{AQI}$ and $\mathrm{PM}_{2.5}$ concentration show consistent variational features, for AQI is highly dependent on $\mathrm{PM}_{2.5}$ concentration.
The ratio of $\mathrm{PM}_{2.5}$ concentration and $\mathrm{AQI}$ is high when $\mathrm{AQI} / \mathrm{PM}_{2.5}$ concentration is high, indicating that fine particles are the main polluted materials during polluted events. In addition, the UVAI is high when AQI/PM ${ }_{2.5}$ concentration is high, with the correlation coefficient of 0.63 and 0.60 respectively. Therefore, the two variables can both be used to describe aerosols in the atmosphere.

During the period October 1-December 31, 2013, three pollution episodes were identified based on the criteria that the AQI was greater than 100 during a continuous 48-h period and the $\mathrm{PM}_{2.5}$ concentration was greater than $174 \mu \mathrm{g} \mathrm{m}^{-3}$. The three episodes occurred during the periods December 3-8, December 19-20 and December 24-26. Eleven typical pollution days were identified and rainy days were excluded to avoid the impact of rainfall on aerosol distribution. Four non-polluted days were identified within five days before and after the pollution episodes with the AQI not exceeding 100. Rainy days within five days before and after the identified non-polluted/pollution days and the day before and after the rainy days were excluded, and the arithmetical averages of the meteorological elements and aerosol data for the remaining days were treated as the background values for comparative analysis.

A large-scale pollution event occurred from late November to early December during 2013. The selected episodes only covered a short period of time, which can to a certain extent remove the influence of solar zenith angle and seasonality. Rainy days and the day before and after the rainy day were excluded to minimize the impacts of clouds and precipitation. In addition, the selection of consecutive days for weather analysis can eliminate the influence of different weather conditions on meteorological elements and surface radiation budget and increase the reliability of the results.

Based on the aforementioned criteria, the background API is 197 and the $\mathrm{PM}_{2.5}$ concentration is $155 \mu \mathrm{g} \mathrm{m}^{-3}$;

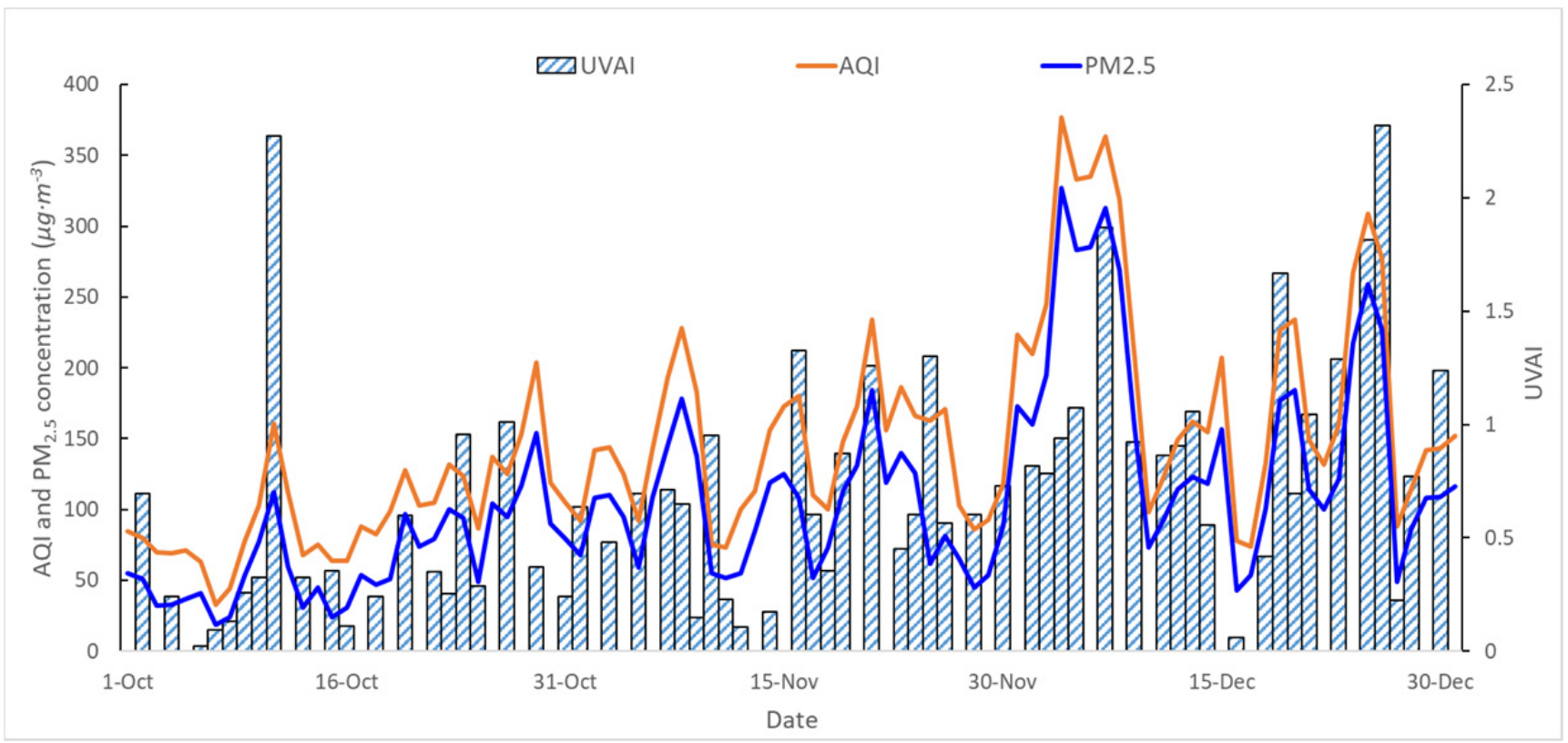

Fig. 2. Time series of daily $\mathrm{PM}_{2.5}$ concentration, AQI and UVAI during the period October 1-December 31, 2013. 
during pollution days, the API is 324 and the $\mathrm{PM}_{2.5}$ concentration is $274 \mu \mathrm{g} \mathrm{m}^{-3}$; during non-polluted days, the API is 91 and the $\mathrm{PM}_{2.5}$ concentration is $55 \mu \mathrm{g} \mathrm{m}^{-3}$. Details can be found in Table 2 .

\section{COMPARATIVE ANALYSIS OF METEOROLOGICAL ELEMETNS AND RADIATION BUDGET UNDER DIFFERENT WETHER CONDITIONS}

\section{Differences in Surface Meteorological Elements}

Aerosol particles are suspended in the atmosphere, affecting surface meteorological elements by influencing direct radiation at the surface. Fig. 3 presents daily surface temperature and $\mathrm{RH}$, pressure, wind speed and wind roses from October to December of 2013 under typical polluted and non-polluted days. Fig. 3(a) shows that the diurnal variations in temperature and $\mathrm{RH}$ are in opposite phases on both non-polluted and polluted days, while they have similar variational patterns on non-polluted and polluted days. The daily average temperature is $4.54^{\circ} \mathrm{C}$ higher on polluted days than on non-polluted days, which might be because aerosols suspended in the air are firstly impacted by temperature, and then reacting to it. Temperature changes on the non-polluted days are always earlier than those on polluted days, indicating that the temperature response to solar radiation is slower on polluted days than on non-polluted days. To interpret this phenomenon, the warm effect of aerosols during night and the cool effect during the daytime would weaken the direct exchange of energy between the land surface and the atmosphere. The $\mathrm{RH}$ is higher on polluted days than that on non-polluted days with an average difference of $26 \%$. The average $\mathrm{RH}$ values are $50.2 \%$ and $76.3 \%$ on polluted days and nonpolluted days, respectively. Changes in RH are possibly caused by hygroscopic growth of aerosols and temperature changes. According to Zhuang et al. (2014), scattering coefficient (SC) for aerosols and high level of visibility are likely found in high $\mathrm{RH}$ ranges. This is consistent with
Ding et al. (2013) that the stagnant meteorology is typically characterized by weak wind speed and high $\mathrm{RH}$ in the formation of polluted events over eastern China. Furthermore, the increased RH tends to favor the hygroscopic growth of aerosols, and could enhance the formation of secondary aerosols (Li et al., 2017). As shown in Fig. 3(b), the diurnal variational pattern in surface pressure on non-polluted and polluted days is similar to the background variation. The average difference between non-polluted and polluted days is $6.6 \mathrm{hPa}$, which is possibly associated with convergence and pollutant accumulation under a low-pressure condition. Fig. 3(c) shows that the wind speed has no distinct diurnal variation on polluted days, and it remains approximately $0.5-1 \mathrm{~m} \mathrm{~s}^{-1}$ on non-polluted days and increases with time later, reaching 2.5-3 $\mathrm{m} \mathrm{s}^{-1}$ during the period 10:00-17:00 local time (LT) and then decreases rapidly to approximately $1 \mathrm{~m} \mathrm{~s}^{-1}$. The wind speed on non-polluted days is higher than that on polluted days with an average difference of $0.88 \mathrm{~m} \mathrm{~s}^{-1}$. This wind speed difference is particularly distinct during the period 10:00-14:00 LT, suggesting that low wind speeds on the YRD are favorable for pollutant accumulation and thus formation of pollution episodes. Figs. 3(d)-3(e) shows wind roses under three weather conditions. In general, westerly and southerly winds prevail with a homogeneous wind speed distribution. On nonpolluted days, westerly winds prevail with a higher wind speed; on polluted days, northwesterly winds prevail with most wind speeds less than $1 \mathrm{~m} \mathrm{~s}^{-1}$.

\section{Differences in Surface Energy Budget}

Aerosols can modify the partitioning of solar energy between atmosphere and land by absorbing and scattering solar radiation, which may influence regional climate. Fig. 4 shows the diurnal variations in surface shortwave, longwave, net radiation flux, and sensible and latent heat fluxes on typical polluted days and non-polluted days and under background conditions.

The diurnal variations in upward and downward shortwave radiation flux on polluted days, non-polluted

Table 1. Instruments used at Lishui Station.

\begin{tabular}{llll}
\hline Instrument name & Instrument type & Observed variables & Company \\
\hline Eddy covariance system & CSAT3, Li-CS7500 & CO2, LE, HS & Campbell, LI-COR \\
Humidity/temperature probe & HMP45C-L & Temperature, RH & Vaisala \\
Soil temperature profile & STP01-L50, 107-L & Soil Temperature & Hukseflux \\
Water content reflectometer & CS616_L & Soil Moisture & Campbell \\
Tipping bucket rain gage & TE525MM_L & Precipitation & Texas Electronics \\
Pyranometer (SW flux) & CM21 & Total/Solar Radiation & Kipp \& Zonen \\
Total sky imager & ASI & Cloud & ASI \\
\hline
\end{tabular}

Table 2. Typical polluted days and non-polluted days and their corresponding aerosol concentrations.

\begin{tabular}{lllllll}
\hline & \multicolumn{2}{c}{ Polluted days } & & \multicolumn{3}{c}{ Non-polluted days } \\
\cline { 1 - 2 } Date & AQI & $\mathrm{PM}_{2.5}\left(\mu \mathrm{g} \mathrm{m}^{-3}\right)$ & & Date & AQI & $\mathrm{PM}_{2.5}\left(\mu \mathrm{g} \mathrm{m}^{-3}\right)$ \\
\hline 03 DEC & 245 & 195 & $28 \mathrm{NOV}$ & 86 & 45 \\
04 DEC & 377 & 327 & $29 \mathrm{NOV}$ & 93 & 54 \\
07 DEC & 363 & 313 & $10 \mathrm{DEC}$ & 98 & 73 \\
25 DEC & 309 & 259 & $27 \mathrm{DEC}$ & 88 & 49 \\
\hline
\end{tabular}



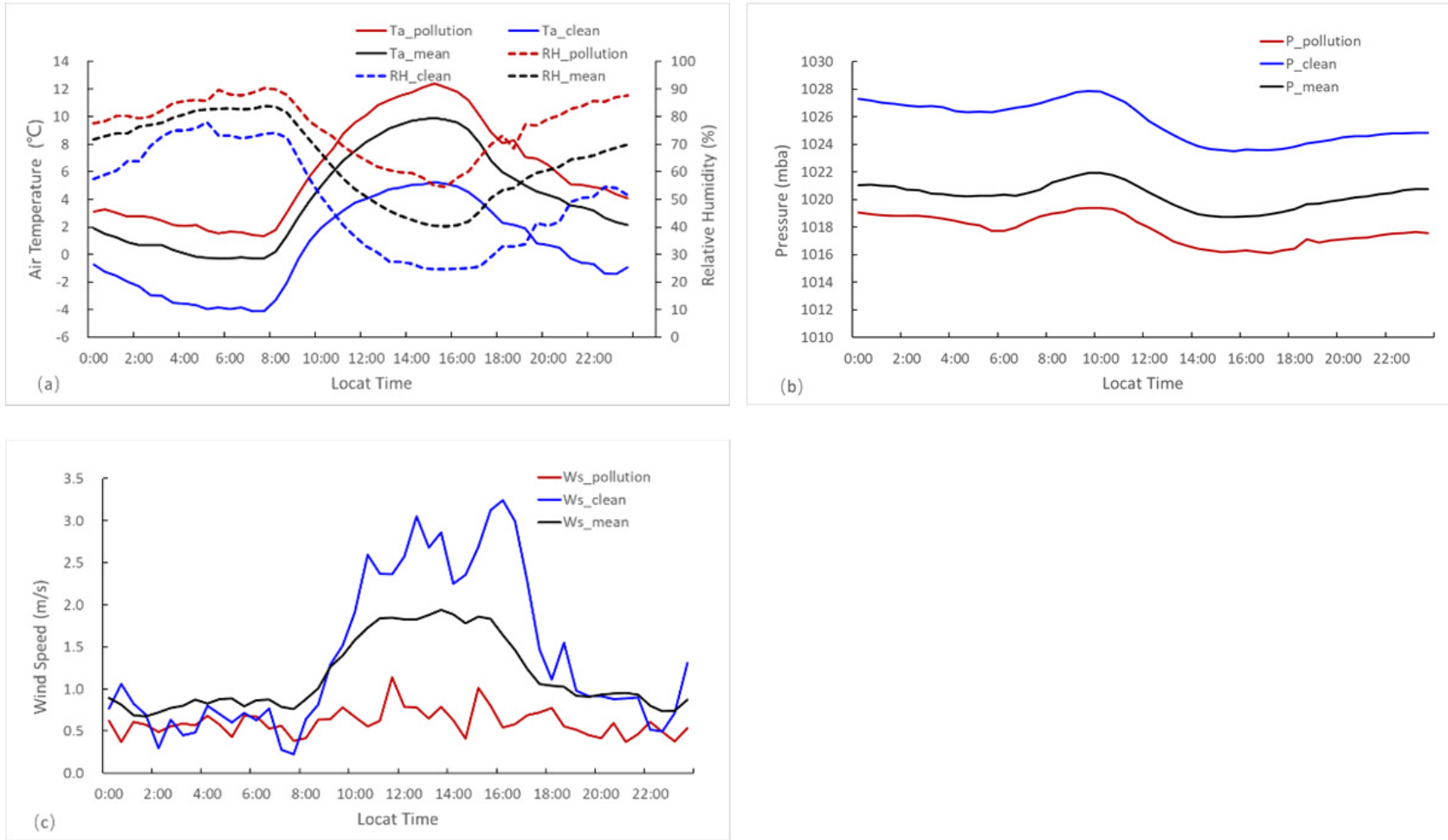

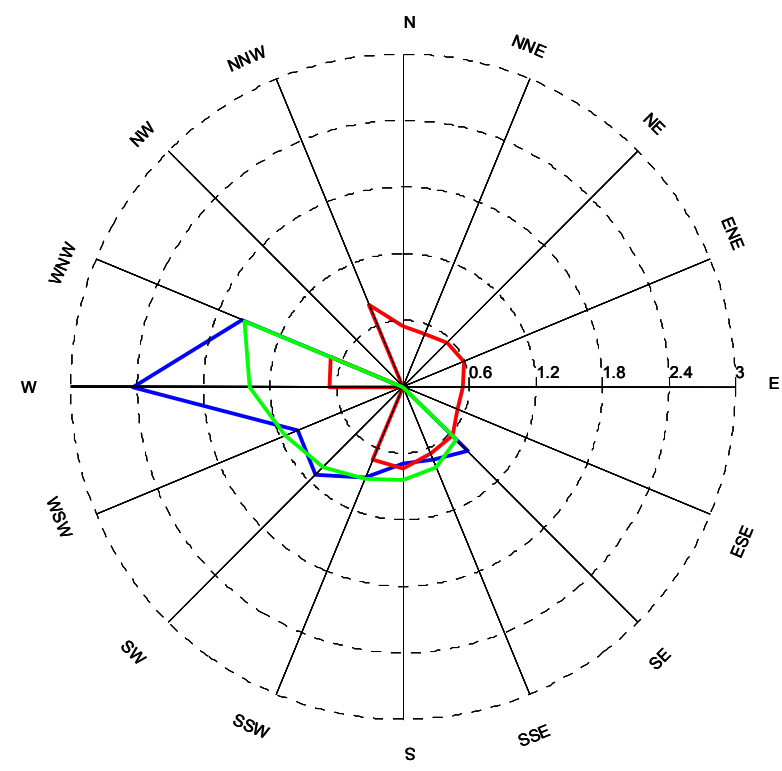

(d) wind roses of wind direction frequency (\%)

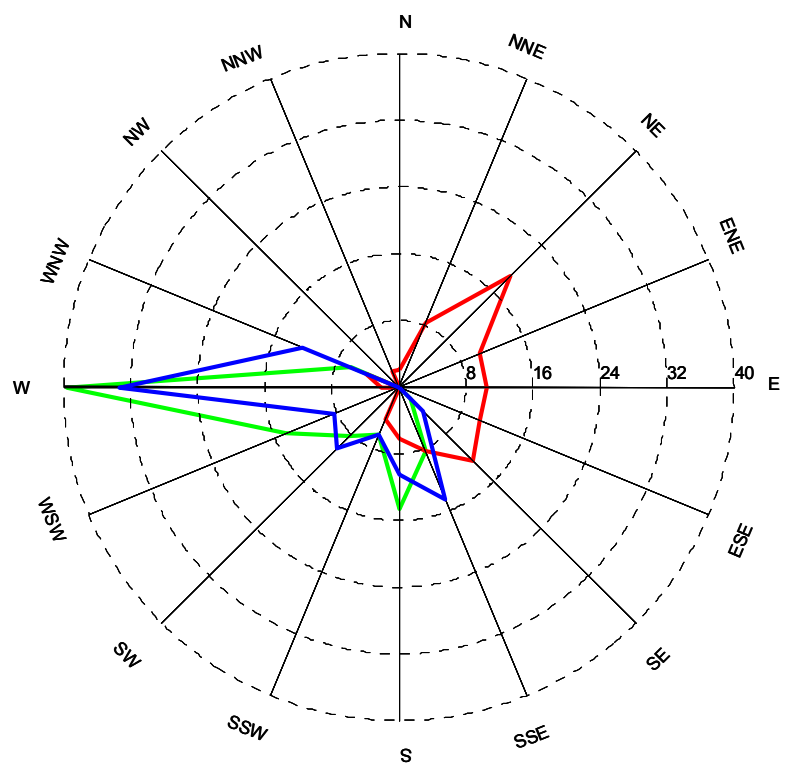

(e) wind roses of wind speed frequency (\%)

Fig. 3. Diurnal variations in surface micro-meteorological elements from October to December of 2013: (a) temperature and $\mathrm{RH}$, (b) surface pressure, (c) wind speed, (d) wind roses of wind direction frequency (\%), and (e) wind roses of wind speed frequency $(\%)$.

days, and under background weather conditions are shown in Fig. 4(a), which shows that upward and downward solar radiation both present a unimodal diurnal variation pattern under the three conditions. During the day, the upward and downward shortwave radiation fluxes are both smaller on polluted days than those on non-polluted days with the largest differences of $280 \mathrm{~W} \mathrm{~m}^{-2}$ and $50 \mathrm{~W} \mathrm{~m}^{-2}$, respectively. It can be deduced that the aerosol particles suspended in the air to some extent reduce the solar radiation that reaches the surface and weakens the solar heating. Reflective solar radiation correspondingly decreases under the same underlying surface condition. Fig. 4(b) shows that longwave radiation flux reaches the surface and upward longwave radiation are both greater on polluted days than on nonpolluted days with differences of $23 \mathrm{~W} \mathrm{~m}^{-2}$ and $63 \mathrm{~W} \mathrm{~m}^{-2}$, respectively. Combined with Fig. 3(a), polluted days are 

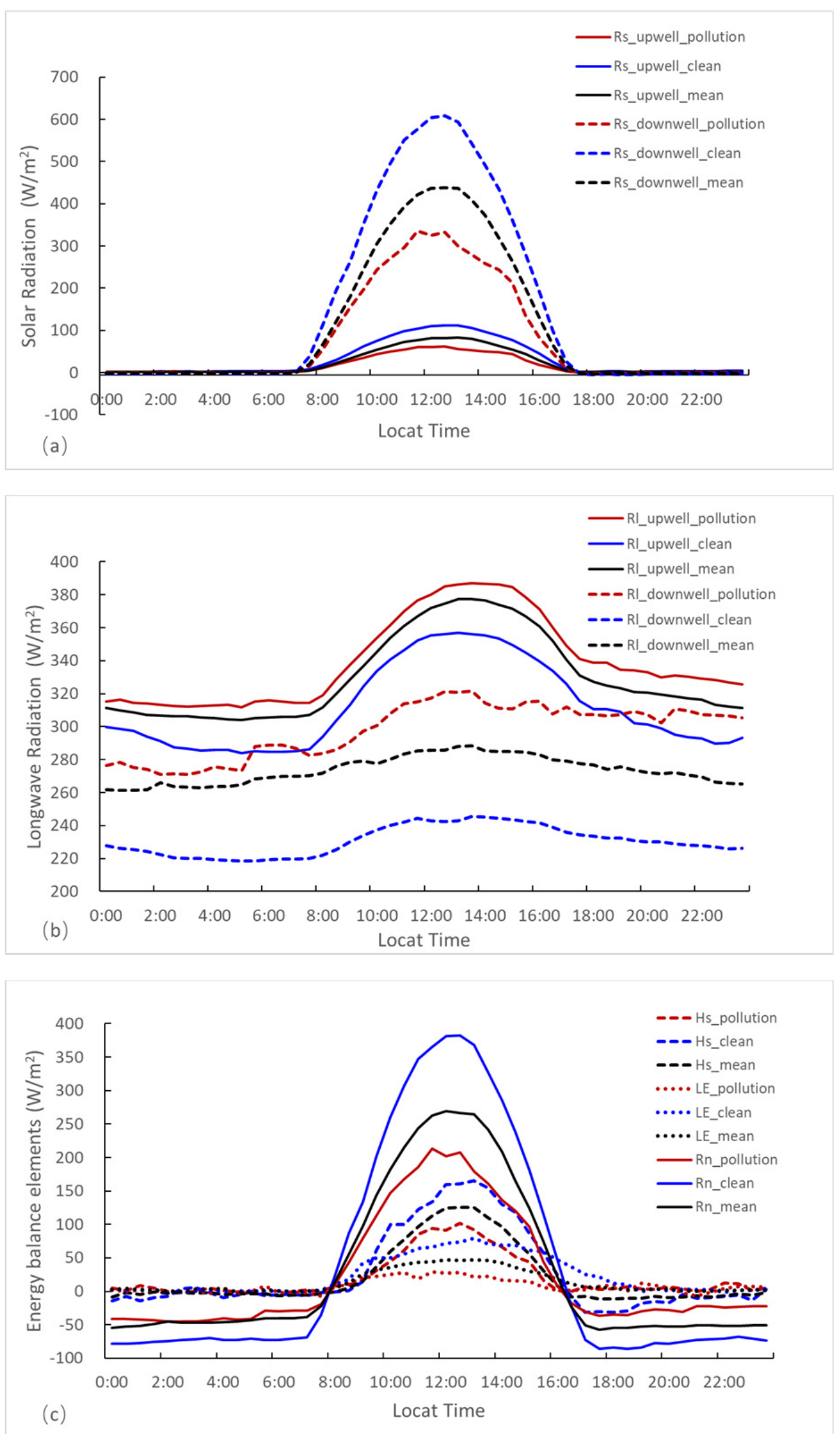

Fig. 4. Diurnal variations of surface energy budget from October to December of 2013 under three typical conditions: (a) shortwave radiation flux (Rs), (b) longwave radiation flux (Rl), (c) net radiation flux (Rn) and sensible and latent heat fluxes (Hs and LE). 
always accompanied by higher temperature, namely, the larger longwave radiation. Furthermore, the longwave radiation emitted from the surface and the lower level of the atmosphere are absorbed and then re-emitted to the surface via aerosol particles suspended in the air. The strong downward longwave radiation can be explained with the heating of absorbing aerosols.

During the day, however, although the aerosol particles still behave similar to an insulation layer because of their impact on longwave radiation, their impact on shortwave radiation is much stronger. Downward shortwave radiation is scattered and reflected by aerosol particles in the air, leading to large decreases in solar radiation that can reach the surface. As a result, net radiation in the surface is much less on polluted days than that on non-polluted days during the day, but slightly greater during the night. As shown in Fig. 4(c), the diurnal variation in surface net radiation presents a unimodal pattern under different weather conditions, while the net radiation flux during the day (08:00-16:00 LT) is much higher on non-polluted days than that on polluted days with a greatest difference of nearly $180 \mathrm{~W} \mathrm{~m}^{-2}$. In contrast, net radiation flux during the night shows little difference under different weather conditions and is only slightly higher on polluted days than on non-polluted days. From the perspective of the entire day, the net radiation flux on polluted days is $19 \mathrm{~W} \mathrm{~m}^{-2}$ less than that on non-polluted days. Therefore, the impact of aerosols on the surfaceatmosphere system is not limited to the aerosol heating effect on the lower atmosphere. Decreases in surface net radiation caused by aerosol radiative effects should also be considered.

Fig. 4(c) shows that the magnitudes of the sensible and latent heat fluxes are equivalent, and their diurnal variations are similar to those of net radiation flux with a unimodal feature. The peak values occur at approximately 12:00 LT. During the day (09:00-15:00 LT), the sensible heat flux is greater than the latent heat flux. Both the sensible and latent heat fluxes during the day are smaller on polluted days than on non-polluted days, suggesting that under a high concentration of aerosols, although solar radiation energy can still be transferred from the surface to the atmosphere during the day, sensible heat flux decreases because of the aerosol absorption of shortwave radiation and the reduced temperature difference between the surface and the atmosphere. On polluted days, the relatively high $\mathrm{RH}$ leads to a decreased difference in $\mathrm{RH}$ between the surface and the atmosphere, and subsequently reduces the latent heat flux. On polluted days, the sensible and latent heat fluxes account for $88 \%$ and $34 \%$ of the total net radiation flux, respectively; on non-polluted days, the values are $64 \%$ and $53 \%$, respectively.

\section{ANALYSIS OF A TYPICAL POLUUTION EPISODE}

To further analyze aerosol impacts on meteorological elements, surface energy budget, and sensible/latent heat fluxes in the urban cluster region of the YRD, a typical heavy pollution episode was selected for analysis in the present study.

\section{Weather Condition}

A severe pollution event occurred during the period of December 2 to 12 in 2013 in eastern China. This pollution episode covered a large area and affected nearly all of central and eastern China. The AQI index reached Level 6, the severe pollution level, in multiple locations such as Tianjin, Hebei, Shandong, Jiangsu, Anhui, Henan, Zhejiang, and Shanghai. Fig. 5 showed the scenario of air pollution days (December 8, 2013) and usual days in Nanjing. The average $\mathrm{PM}_{2.5}$ concentration was greater than $150 \mu \mathrm{g} \mathrm{m}^{-3}$ and the value reached $300-500 \mu \mathrm{g} \mathrm{m}^{-3}$ in some areas. The most severe pollution occurred in central and southern Jiangsu, and the air quality in Nanjing reached the extremely severe pollution level for five consecutive days and the severe level for nine consecutive days. The $\mathrm{PM}_{2.5}$

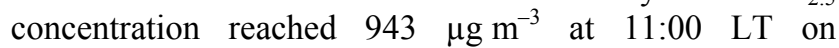
December 3, 2013.

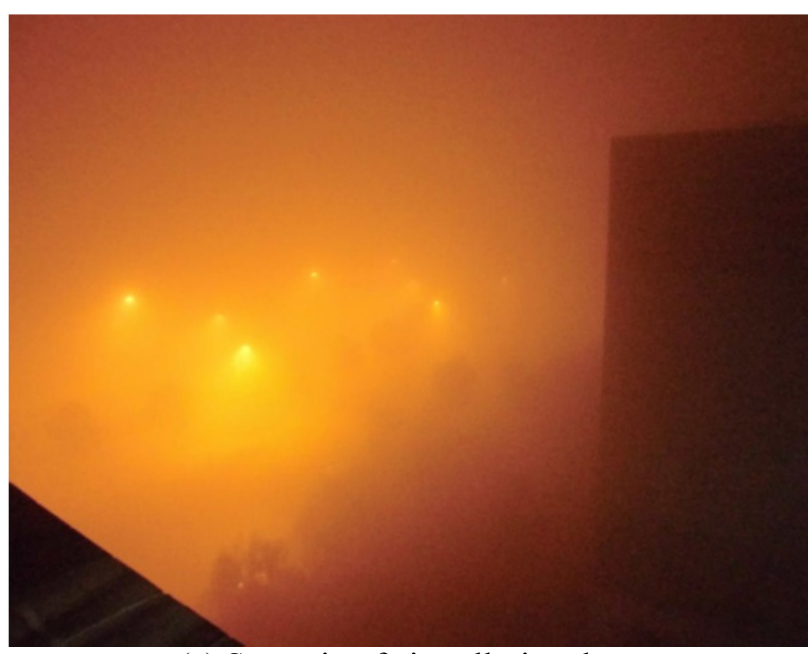

(a) Scenario of air pollution days

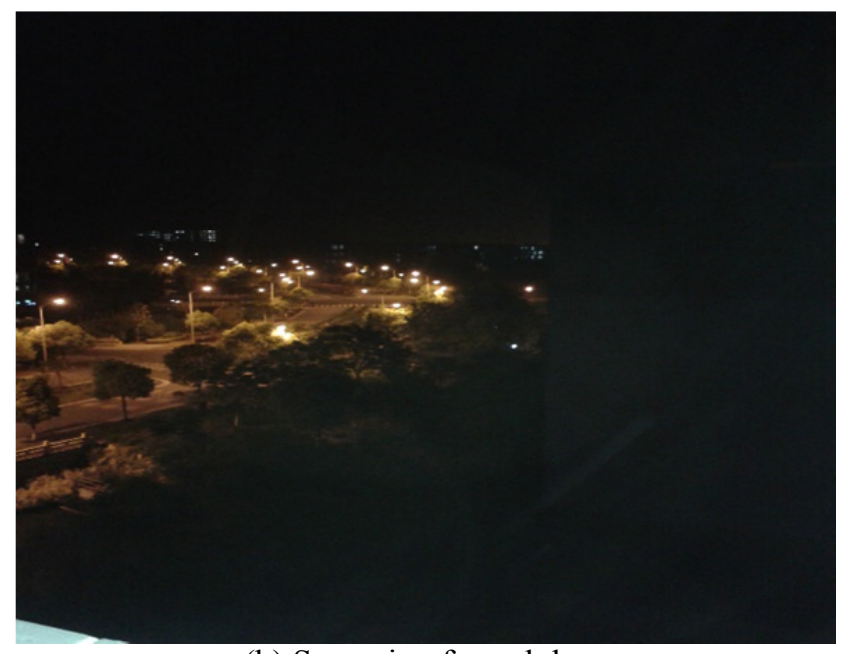

(b) Scenario of usual days

Fig. 5. (a) A polluted day (December 8, 2013) and (b) a normal day at the Xianlin campus of Nanjing University. 
Fig. 6 shows the geopotential height fields at (a, c) 500 $\mathrm{hPa}$ and $(\mathrm{b}, \mathrm{d}) 850 \mathrm{hPa}$ at 12:00 UTC on $(\mathrm{a}, \mathrm{b})$ December 5 and (c, d) December 10, 2013, representing the synoptic situation for the polluted and non-polluted day respectively. The 4-times daily geopotential height data (Kalnay et al., 1996) with the resolution of $1^{\circ} \times 1^{\circ}$ is obtained from the National Center for Atmospheric Research (NCAR). The region of $70-140^{\circ} \mathrm{E}, 20-60^{\circ} \mathrm{N}$ is used to analyze the background circulation, and the location of $31^{\circ} 43^{\prime} \mathrm{N}$, $118^{\circ} 58^{\prime} \mathrm{E}$ is treated as the Lishui station. On December 5, there was a gentle westerly air stream prevailing at the $500 \mathrm{hPa}$ over eastern China without significant trough and ridge. At the $850 \mathrm{hPa}$ level, the isopiestic line is sparse over the eastern China. This configuration of high-level and low-level synoptic situation is stable, which suppress the diffusion of aerosols. On December 10, the density of isopiestic line is higher over eastern China, which favor to the pollutant dispersion.

\section{Changes in Surface Meteorological Elements}

Fig. 7 shows daily changes in surface pressure, temperature, $\mathrm{RH}$, and wind speed from November 28 to December 13 of 2013. Fig. 7(a) shows that the surface pressure oscillated at approximately $1025 \mathrm{hPa}$ on November 28 , and then rapidly decreased, accompanied by a rapid increase in the pollutant concentration. During several days of heavy pollution, the surface pressure oscillated at approximately $1015 \mathrm{hPa}$; following December 9, the surface pressure gradually increased, and the pollution episode ended. It is clear that changes in surface pressure and pollutant concentration are negatively correlated. Low surface pressure and weak convergence of airflow suppressed the diffusion of aerosols during the developing stage of this severe pollution episode. As shown in Fig. 7(b), daily changes in temperature were in opposite phase to those of $\mathrm{RH}$ during the entire process, and the magnitude of the diurnal variation for temperature on the polluted days was higher at the outbreak of the pollution episode than on the other days. During the late stage of the pollution episode, the temperature began to decrease, suggesting that the aerosol particles suspended in the air effectively dissipated the solar radiation and reduced the surface net radiation. Furthermore, the case study method cannot eliminate the influence of synoptic situation. RH was higher on the polluted days than on the other days, and nearly reached a saturation level on December 7 and 8. During the pollution event (Fig. 7(c)) from November 28 to December 4, the surface wind speed was low all of the time and the concentration of pollutants remained high. The wind speed was approximately $1 \mathrm{~m} \mathrm{~s}^{-1}$ during the period of December 4-8 without distinct diurnal variation. During the late stage of the pollution episode, the wind speed showed a rapid increase. It can be deduced that during this pollution episode, the weak wind speed undermined dispersion and caused pollutant accumulation, resulting in the outbreak. The rapid increase in wind speed during the later stage of the (a) $1200 \mathrm{LT}$ for $4 \mathrm{DEC} 2013$ for $500 \mathrm{hPa}$

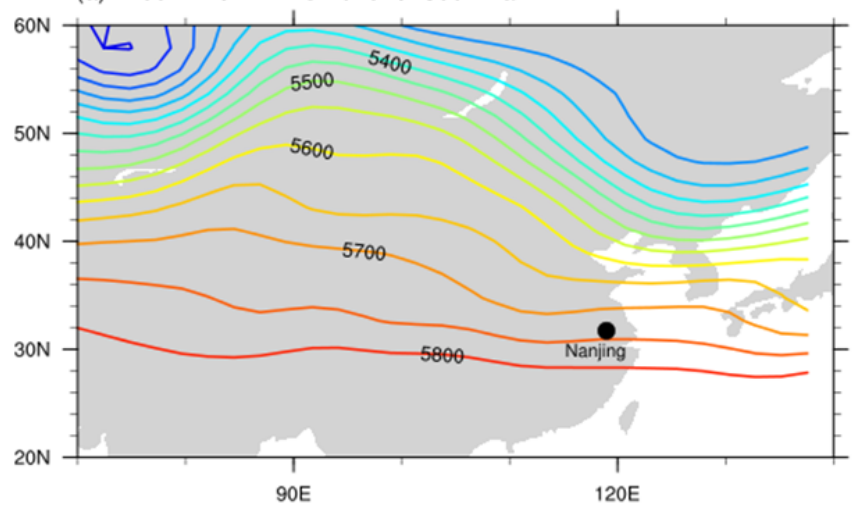

(c) $1200 \mathrm{LT}$ for $10 \mathrm{DEC} 2013$ for $500 \mathrm{hPa}$

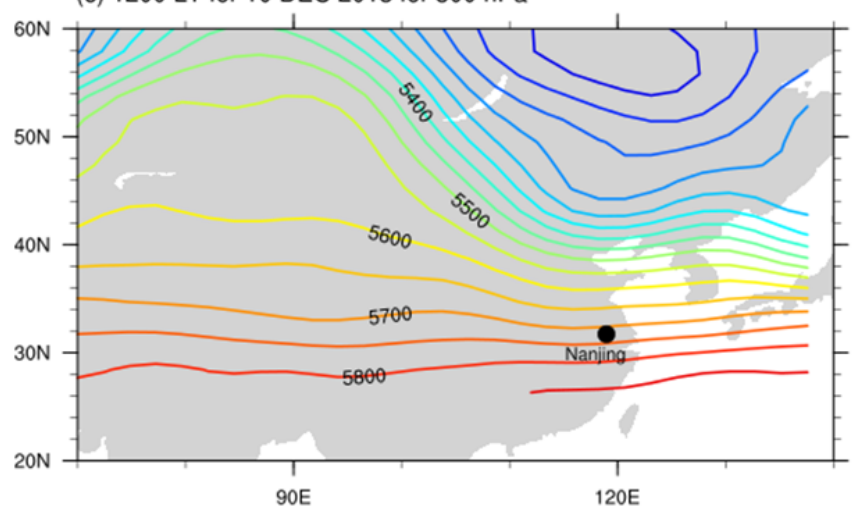

(b) $1200 \mathrm{LT}$ for $4 \mathrm{DEC} 2013$ for $850 \mathrm{hPa}$

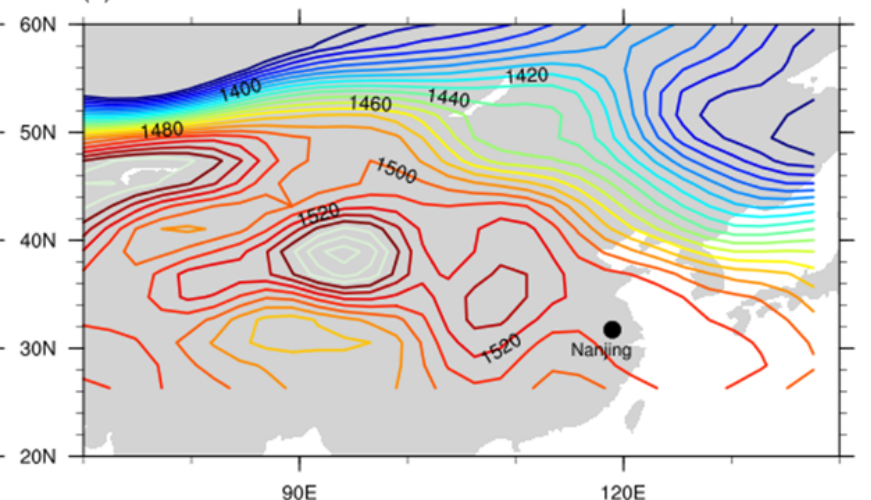

(d) $1200 \mathrm{LT}$ for $10 \mathrm{DEC} 2013$ for $850 \mathrm{hPa}$

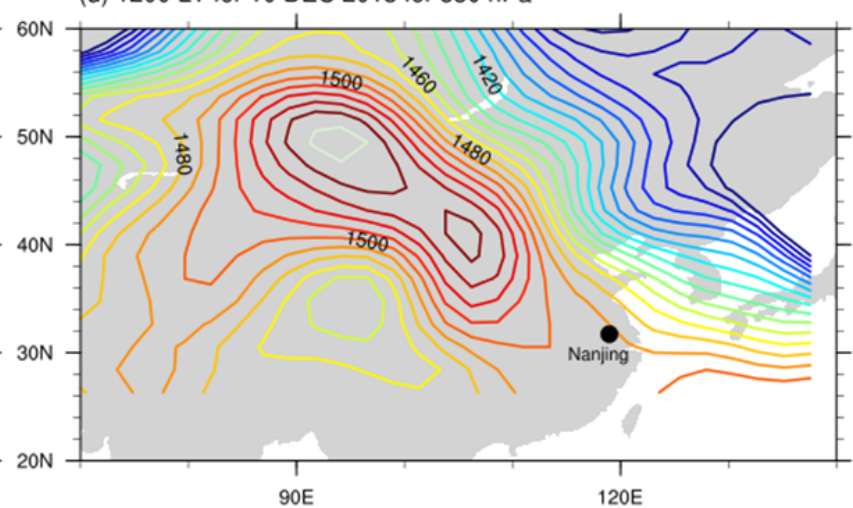

Fig. 6. Geopotential height (in dagpm) fields at (a, c) $500 \mathrm{hPa}$ and (b, d) $850 \mathrm{hPa}$ at 12:00 UTC on (a, b) December 5 and (c, d) December 10, 2013. 

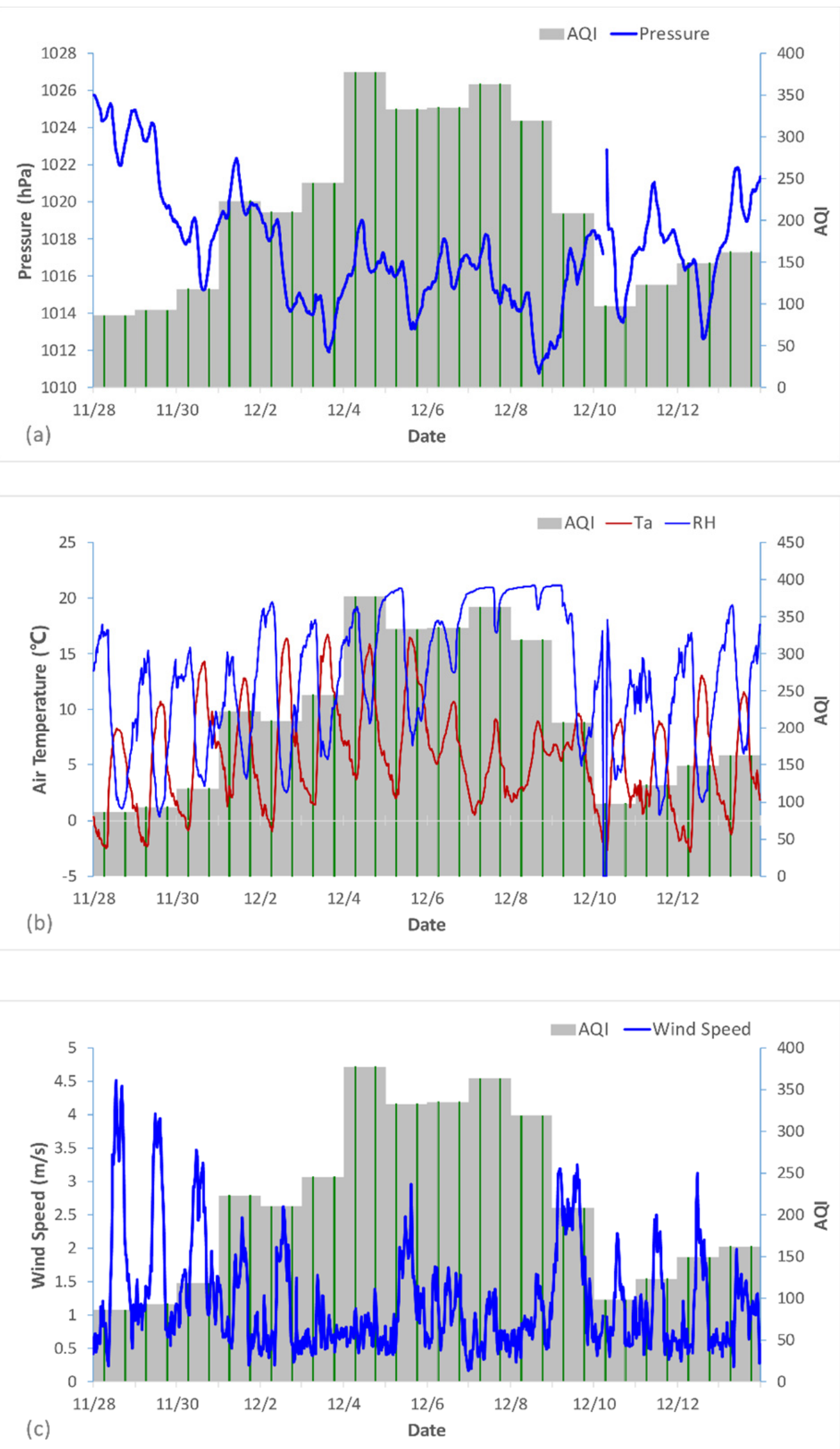

Fig. 7. Daily changes in the surface micro-meteorological elements from November 28 to December 14, 2013: (a) surface pressure, (b) temperature and $\mathrm{RH}$, and (c) wind speed. The green lines are utilized to mark the daytime and nighttime. 
pollution episode provided a favorable condition for dispersion of pollutants and the event ended.

\section{Changes in Surface Radiation Budget and Energy Balance}

Daily changes in each variable of the surface radiation budget are shown in Fig. 8, which shows significant responses of these variables to changes in aerosol concentration. Combined with Figs. 8(a)-8(b), it can be seen that aerosols reduced the net surface radiation mainly via a reduction in downward solar radiation during the day. With the same surface albedo, upward solar radiation consequently decreased. Under a condition of severe pollution, downward longwave radiation at the surface was much higher than on non-polluted days, indicating that the upward longwave radiation emitted by the surface was reflected back to the surface via aerosol particles suspended in the air. The aerosol particles behaved similar to an insulation layer. Fig. 8(c) shows that from December 3 to 8 , the net surface radiation was distinctly lower than that on the non-polluted days, and the peak value of net radiation on December 7 was $240 \mathrm{~W} \mathrm{~m}^{-2}$ less than that on December 8. Following the decrease in surface net radiation, the partitions to sensible and latent heat fluxes correspondingly decreased. During the entire process, the sensible heat flux always remained larger than the latent heat flux, which can be attributed to the decreased temperature difference between the surface and the atmosphere and the weakened sensible heat flux exchange.

\section{Response of Dynamic Variables in the Surface}

Temporal variations in dynamic variables during the pollution event are shown in Fig. 9, which were used to analyze fluctuations of horizontal and vertical wind components. Fig. 9(a) show the variance of vertical wind speed, reflecting the turbulence of atmosphere. During the polluted days, the fluctuation of vertical air velocity is small, indicating stable atmospheric, which suppress the diffusion of aerosols. During the late stage of the pollution episode, vertical wind velocity fluctuations gradually increased and air turbulence intensified. As a result, the pollutant concentration decreased. The change pattern for horizontal wind speed variance (Fig. 9(b)) is similar to the vertical wind speed, with the lowest value during the polluted days. Both $\mathrm{U}$ and $\mathrm{V}$ components reached their maximum at 19:00 LT. The largest value for momentum and variance of horizontal wind speed can be found on December 9 when aerosol concentration began to decrease, meaning that strong wind speed fluctuation can favor the diffusion of aerosols. Fig. 9(c) shows the covariance between the vertical and horizontal winds, which reflects the correlative relationship between horizontal and vertical winds during this pollution episode. During the pollution event, the $\mathrm{v}$ and $\mathrm{w}$ show positive relationship, implying that the aerosols might come from the north of Nanjing. During this pollution event, high aerosols concentration is associated with low wind speed. It can be seen that accompanied by strong wind speed fluctuations during the period of November 28 to 30 , pollutants rapidly accumulated and mixed in the region, leading to the outbreak. Since that time, vertical wind speed fluctuations significantly weakened, suggesting that turbulence was weak and the condition was unfavorable for pollutant dispersal. During the late stage of the episode, vertical wind speed fluctuations gradually intensified with stronger turbulence, and the pollutant concentration decreased.

\section{DISCUSSION AND CONCLUSION}

In this study, the meteorological elements and surface energy balance during different pollution conditions were compared. A typical pollution episode was also analyzed. The major conclusions are as follows:

(1) Over the urban cluster area of the YRD, represented by Nanjing, the mean daily temperature is approximately $4.5^{\circ} \mathrm{C}$ higher, the $\mathrm{RH}$ is $26 \%$ higher, the surface pressure is $6.6 \mathrm{hPa}$ lower, and the wind speed is $60 \%$ lower on polluted days than on non-polluted days. Northeasterly winds prevail on the polluted days.

(2) Radiative aerosol effects lead to decreased net surface radiation, resulting in a maximum difference of $180 \mathrm{~W} \mathrm{~m}^{-2}$ between polluted and non-polluted days. The maximum sensible and latent heat fluxes account for $88 \%$ and $34 \%$, and $64 \%$ and $53 \%$ of the net radiation on polluted and non-polluted days, respectively.

(3) Prior to the onset of the pollution event from November 28 to December 14, 2013, the surface pressure dropped, and the wind speed rapidly decreased. During the period of high aerosol concentrations, both the surface pressure and wind speed remained low, thus inhibiting pollutant dispersion. Additionally, the surface temperature was distinctly higher during the onset of the pollution episode than prior to it, and the $\mathrm{RH}$ increased. Accompanied by an increase in wind speed and surface pressure as well as temperature, the meteorological conditions became favorable to pollutant dispersion. On polluted days, the net surface radiation flux, upward and downward shortwave radiation fluxes, and latent and sensible heat fluxes decreased.

(4) During the pollution process, changes in the vertical velocity fluctuation were consistent with changes in the variance of horizontal wind speed. During the polluted days, the wind speed fluctuations remained low, turbulence was weak, and pollutants could not easily disperse. During the latter stage of the pollution episode, the vertical wind velocity fluctuations gradually increased, and turbulence intensified. As a result, the pollutant concentration decreased.

Because the samples used in the present study are limited, these results must be further verified against long-term observations. Furthermore, the sources of pollutants in urban cluster regions are often complex, and the radiative effects of various pollutants on different physical and chemical properties may vary. Therefore, further analysis of aerosol impacts over an urban cluster region based on the different sources and properties of the pollutants is required, as is the application of explicit models for better understanding the mechanisms regulating aerosol-radiation interaction. 

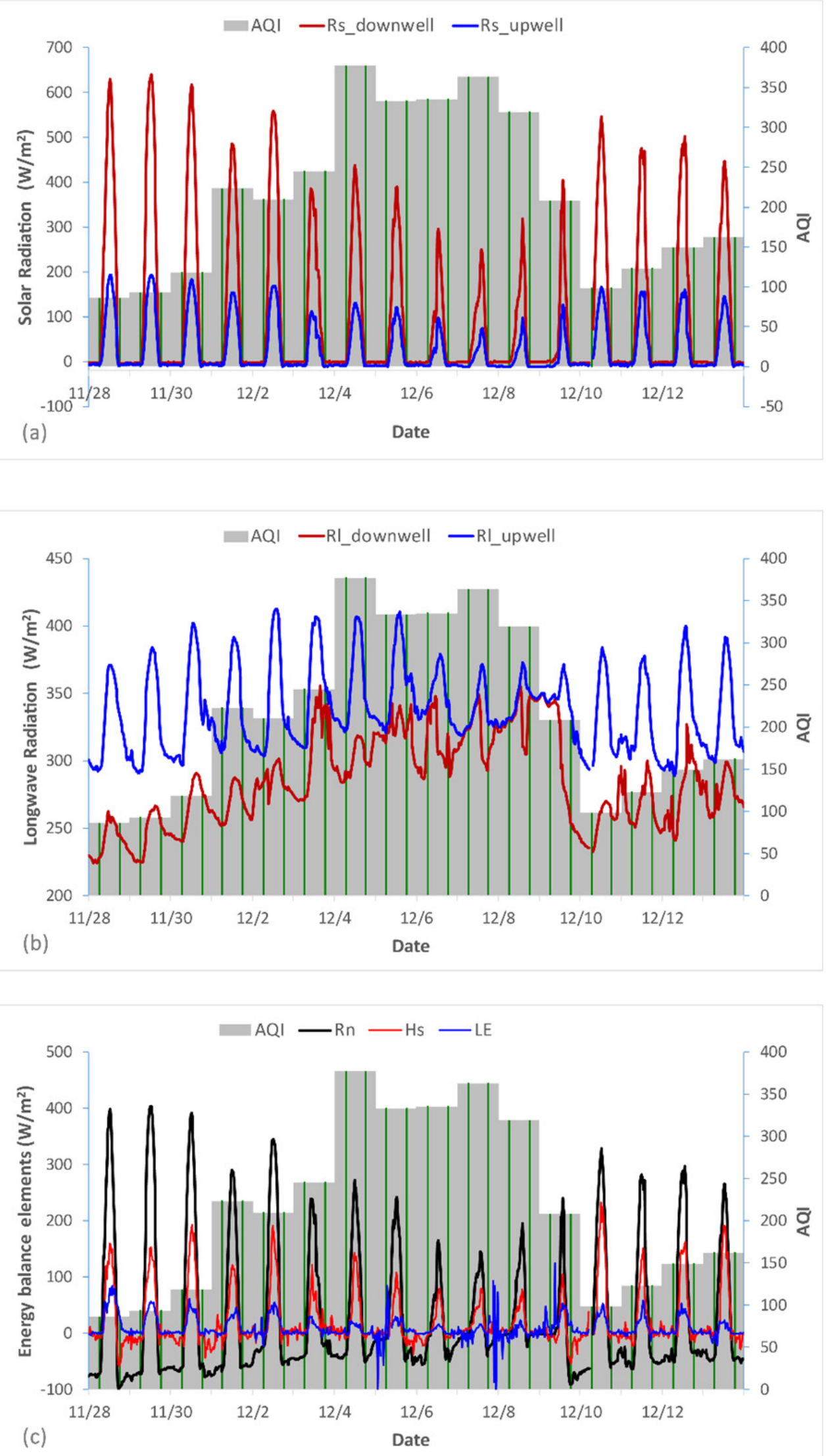

Fig. 8. Daily changes in each individual term of the surface radiation budget from November 28 to December 14: (a) surface shortwave radiation flux, (b) longwave radiation flux, and (c) net radiation flux and sensible and latent heat fluxes. The green lines are utilized to mark the daytime and nighttime. 

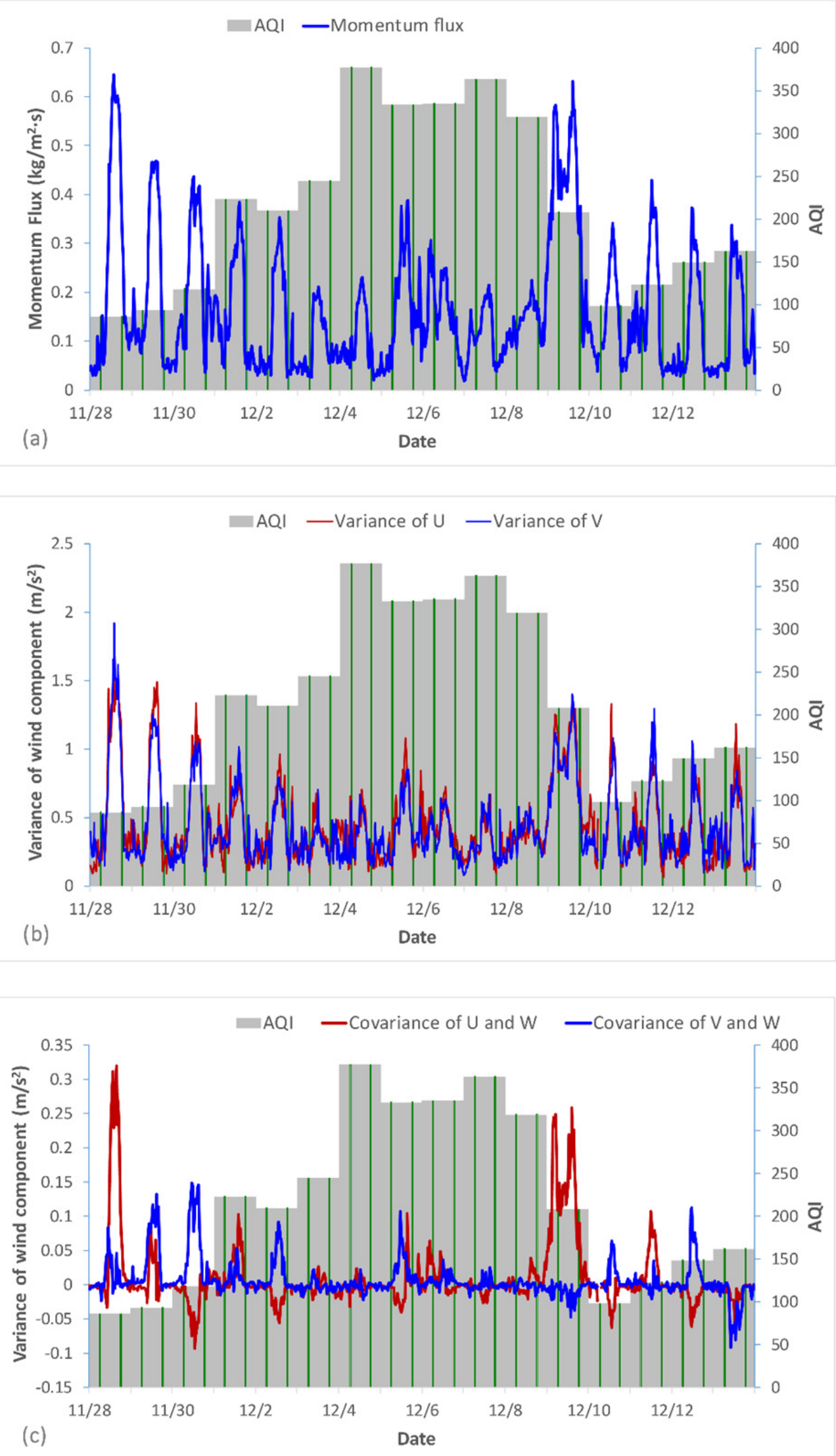

Fig. 9. Daily changes in the dynamic variables from November 28 to December 13, 2013: (a) vertical wind speed variance, (b) horizontal wind speed variance, and (c) covariance of vertical and horizontal wind speeds. The green lines are utilized to mark the daytime and nighttime. 


\section{ACKNOWLEDGEMENTS}

This work was supported by the National Natural Science Foundation of China (Grant No: 41705101). This work was also supported by the Jiangsu Collaborative Innovation Center for Climate Change.

\section{REFERENCES}

Ahmad, S.P., Levelt, P.F., Bhartia, P.K., Hilsenrath, E., Leppelmeier, G.W. and Johnson, J.E. (2003). Atmospheric products from the ozone monitoring instrument (OMI). Proc. SPIE 5151, Earth Observing Systems VIII. Barnes, W.L. (Ed.), Optical Science and Technology, SPIE's $48^{\text {th }}$ Annual Meeting, 3-8 August 2003, San Diego, California, USA.

Cai, Z., Jiang, F., Chen, J.M., Jiang, Z.Q. and Wang, X.Y. (2018). Weather condition dominates regional $\mathrm{PM}_{2.5}$ pollutions in the eastern coastal provinces of China during winter. Aerosol Air Qual. Res. 18: 969-980, doi: 10.4209/aaqr.2017.04.0140.

Che, H.Z., Shi, G.Y., Zhang, X.Y., Arimoto, R., Zhao, J.Q., Xu, L., Wang, B. and Chen, Z.H. (2005). Analysis of 40 years of solar radiation data from China, 19612000. Geophys. Res. Lett. 32: L06803, doi: 10.1029/2004GL022322.

Chen, H., Gu, X., Cheng, T., Li, Z. and Yu, T. (2013a). The spatial-temporal variations in optical properties of atmosphere aerosols derived from AERONET dataset over China. Meteorol. Atmos. Phys. 122: 65-73, doi: 10.1007/s00703-013-0268-2.

Chen, Y.Y., Ebenstein, A., Greenstone, M., and Li, H.B. (2013b). Evidence on the impact of sustained exposure to air pollution on life expectancy from China's Huai River policy. Proc. Natl. Acad. Sci. U.S.A. 110: 1293612941, doi: 10.1073/pnas.1300018110.

Ding, A.J., Fu, C.B., Yang, X.Q., Sun, J.N., Petäjä, T., Kerminen, V.M., Wang, T., Xie, Y., Herrmann, E., Zheng, L.F., Nie, W., Liu, Q., Wei, X.L. and Kulmala, M. (2013). Intense atmospheric pollution modifies weather: A case of mixed biomass burning with fossil fuel combustion pollution in eastern China. Atmos. Chem. Phys. 13: 10545-10554, doi: 10.5194/acp-13-10545-2013.

Fan, J.W., Zhang, R.Y., Tao, W.K. and Mohr, K.I. (2008). Effects of aerosol optical properties on deep convective clouds and radiative forcing. J. Geophys. Res. 113: D08209, doi: 10.1029/2007JD009257.

Guo, J., Deng, M., Lee, S.S., Wang, F., Li, Z., Zhai, P., Liu, H., Lv, W., Yao, W. and Li X. (2016a). Delaying precipitation and lightning by air pollution over the Pearl River Delta. Part I: Observational analyses. J. Geophys. Res. 121: 6472-6488, doi: 10.1002/2015JD023257.

Guo, J.P., Zhang, X.Y., Wu, Y.R., Zhaxi, Y.Z., Che, H.Z., La, B., Wang, W. and Li, X.W. (2011). Spatio-temporal variation trends of satellite-based aerosol optical depth in China during 1980-2008. Atmos. Environ. 45: 68026811, doi: 10.1016/j.atmosenv.2011.03.068.

Guo, W.D., Wang, X.Q., Sun, J.N., Ding, A.J. and Zou, J. (2016b). Comparison of land-atmosphere interaction at different surface types in the mid- to lower reaches of the Yangtze River valley. Atmos. Chem. Phys. 16: 9875-9890, doi: 10.5194/acp-16-9875-2016.

Han, Z.W., Li, J.W., Guo, W.D., Xiong, Z. and Zhang, W. (2013). A study of dust radiative feedback on dust cycle and meteorology over East Asia by a coupled regional climate-chemistry-aerosol model. Atmos. Environ. 68: 54-63, doi: 10.1016/j.atmosenv.2012.11.032.

Helmert, J., Heinold, B., Tegen, I., Hellmuth, O. and Wendisch, M. (2007). On the direct and semidirect effects of Saharan dust over Europe: A modeling study. $J$. Geophys. Res. 112: D13208, doi: 10.1029/2006JD007444.

Huang, J.P., Lin, B., Minnis, P., Wang, T.H., Wang, X., $\mathrm{Hu}$, Y.X., Yi, Y.H. and Ayers, J.K. (2006) Satellitebased assessment of possible dust aerosols semi-direct effect on cloud water path over East Asia. Geophys. Res. Lett. 33: L19802, doi: 10.1029/2006GL026561.

Huang, X., Ding, A.J., Liu, L.X., Liu, Q., Ding, K., Niu, X.R., Nie, W., Xu, Z., Chi, X.G., Wang, M.H., Sun, J.N., Guo, W.D. and Fu, C.B. (2016). Effects of aerosolradiation interaction on precipitation during biomassburning season in East China. Atmos. Chem. Phys. 16: 10063-10082.

Huang, X., Song, Y., Zhao, C., Cai, X., Zhang, H. and Zhu, T. (2015). Direct radiative effect by multicomponent aerosol over China. J. Clim. 28: 3472-3495, doi: 10.1175/Jcli-D-14-00365.1.

Intergovernmental Panel on Climate Change (IPCC) (2013). The Physical Science Basis, in Contribution of Working Group I to the Fifth Assessment Report of the Intergovernmental Panel on Climate Change, Stocker, T.F. et al. (Eds.), Cambridge Univ. Press, Cambridge, U. K., and New York.

Jin, Q.J., Wei, J.F. and Yang, Z.L. (2014). Positive response of Indian summer rainfall to Middle East dust. Geophy. Res. Lett. 41: 4068-4074, doi: 10.1002/2014GL059980.

Kalnay, E., Kanamitsu, M., Kistler, R., Collins, W., Deaven, D., Gandin, L., Iredell, M., Saha, S., White, G., Woollen, J., Zhu, Y., Chelliah, M., Ebisuzaki, W., Higgins, W., Janowiak, J., Mo, K.C., Ropelewski, C., Wang, J., Leetmaa, A., Reynolds, R., Jenne, R. and Joseph, D. (1996). The NECP/NCAR 40-year reanalysis project. Bull. Amer. Meteor. Soc. 77: 437-471.

Koch, D. and Del Genio, A.D. (2010). Black carbon semidirect effects on cloud cover: Review and synthesis. Atmos. Chem. Phys. 10: 7685-7696, doi: 10.5194/acp10-7685-2010.

Koren, I., Kaufman, Y.J., Remer, L.A. and Martins, J.V. (2004). Measurement of the effect of amazon smoke on inhibition of cloud formation. Science 303: 1342-1345.

Lee, S.S., Guo, J. and Li, Z. (2016). Delaying precipitation by air pollution over the Pearl River Delta: 2. Model simulations. J. Geophys. Res. 121: 11739-11760, doi: 10.1002/2015JD024362.

Li, C., Mao, J., Lau, K.H.A., Chen, J.C., Yuan, Z., Liu, X., Zhu, A. and Liu, G. (2003). Characteristics of distribution and seasonal variation of aerosol optical depth in eastern China with MODIS products. Chin. Sci. Bull. 48: 24882495. 
Li, H.D., Meier, F., Lee, X.H., Chakraborty, T., Liu, J.F., Schaap, M. and Sodoudi, S. (2018). Interaction between urban heat island and urban pollution island during summer in Berlin. Sci. Total Environ. 636: 818-828, doi: 10.1016/j.scitotenv.2018.04.254.

Li, Y.K., Chao, J.P. and Kuang, G.X. (2015). Dynamic and thermodynamic analysis of the urban heat island effect and aerosol concentration. Chin. J. Geophys. 58: 729740, doi: 10.6038/cjg20150303.

Li, Z., Lau, W.K.M., Ramanathan, V., Wu, G., Ding, Y., Manoj, M.G., Liu, J., Qian, Y., Li, J., Zhou, T., Fan, J., Rosenfeld, D., Ming, Y., Wang, Y., Huang, J., Wang, B., Xu, X., Lee, S.S., Cribb, M., Zhang, F., Yang, X., Zhao, C., Takemura, T., Wang, K., Xia, X., Yin, Y., Zhang, H., Guo, J., Zhai, P.M., Sugimoto, N., Babu, S.S. and Brasseur, G.P. (2016). Aerosol and monsoon climate interactions over Asia. Rev. Geophys. 54: 866-929, doi: 10.1002/2015RG000500.

Li, Z., Guo, J., Ding, A., Liao, H., Liu, J., Sun, Y., Wang, T., Xue, H., Zhang, H. and Zhu, B. (2017). Aerosol and boundary-layer interactions and impact on air quality. Natl. Sci. Rev. 4: 810-833, doi: 0.1093/nsr/nwx117.

Ling, X.L., Guo, W.D. and Fu, C.B. (2014). Composite analysis of impacts of dust aerosols on surface atmospheric variables and energy budgets in a semiarid region of China. J. Geophys. Res. 119: 3107-3123, doi: 10.1002/2013JD020274.

Liu, B.M., Ma, Y.Y., Gong, W., Zhang, M., Wang, W. and Shi, Y.F. (2018). Comparison of AOD from CALIPSO, MODIS, and sun photometer under different conditions over central China. Sci. Rep. 8: 10066, doi: 10.1038/s415 98-018-28417-7.

Liu, Y., Sun, J.R. and Bai, Y. (2009). The effects of black carbon and sulphate aerosols in China regions on East Asia monsoons. Tellus B 61: 642-656, doi: 10.1111/j.16 00-0889.2009.00427.x.

Luo, Y.F., Li, W.L. and Zhou, X.J. (2001). Analysis of the 1980's atmospheric aerosol optical depth over China. Acta Meteor. Sinica 59: 77-87.

Miller, R.L. and Tegen, I. (1998). Climate response to soil dust aerosols. J. Clim. 11: 3247-3267, doi: 10.1175/15200442 .

Nie, W., Ding, A.J., Xie, Y.N., Xu, Z., Mao, H., Kerminen, V.M., Zheng, L.F., Qi, X.M., Huang, X., Yang, X.Q., Sun, J.N., Herrmann, E., Petäjä, T., Kulmala, M. and Fu, C.B. (2015). Influence of biomass burning plums on HONO chemistry in eastern China. Atmos. Chem. Phys. 15: 1147-1159, doi: 10.5194/acp-15-1147-2015.

Parajuli, S.P., Gherboudj, I. and Ghedira, H. (2013). The effect of soil moisture and wind speed on aerosol optical thickness retrieval in a desert environment using SEVIRI thermal channels. Int. J. Remote Sens. 34: 5054-5071, doi: 10.1080/01431161.2013.788262.

Peter, C.R., Gassó, S., Ahn, C., Buchard, V., da Silva, A.M. and Torres, O. (2017). Simulation of the Ozone Monitoring Instrument aerosol index using the NASA Goddard Earth Observing System aerosol reanalysis products. Atmos. Meas. Tech. 10: 4121-4134.

Qian, Y., Kaiser, D.P., Leung, L.R. and Xu, M. (2006).
More frequent cloud-free sky and less surface solar radiation in China from 1955 to 2000. Geophy. Res. Lett. 33: L01812, doi: 10.1029/2005GL024586.

Qian, Y., Wang, W. G., Leung, L.R. and Kaiser, D.P. (2007). Variability of solar radiation under cloud-free skies in China: The role of aerosols. Geophys. Res. Lett. 34: L12804, doi: 10.1029/2006GL028800.

Qian, Y., Leung, L.R., Ghan, S.J. and Giorgi, F. (2011). Regional climate effects of aerosols over China: Modeling and observations. Tellus B 55: 914-934, doi: 10.3402/tellusb.v55i4.16379.

Rasheed, A., Aneja, V.P., Aiyyer, A. and Rafique, U. (2015). Measurement and Analysis of fine particulate matter $\left(\mathrm{PM}_{2.5}\right)$ in urban areas of Pakistan. Aerosol Air Qual. Res. 15: 426-439, doi: 10.4209/aaqr.2014.10.0269.

Ren, L.H., Zhang, R.J., Bai, Z.P., Chen, J.H., Liu, H.J., Zhang, M.G., Yang, X.Y. and Zhang, L.M. (2012). Aircraft measurements of ionic and elemental components in $\mathrm{PM}_{2.5}$ over eastern coastal area of China. Aerosol Air Qual. Res. 12: 1237-1246, doi: 10.4209/aaqr. 2011.11.0224.

Richter, A., Burrows, J.P., Nup, H., Granier, C. and Niemeier, U. (2005). Increase in tropospheric nitrogen dioxide over China observed from space. Nature 437: 129-132, doi: 10.1038/nature04092.

Shen, Y.C., Virkkula, A., Ding, A.J., Wang, J.P., Chi, X.G., Nie, W., Qi, X.M., Huang, X., Liu, Q., Zheng, L.F., Xu, Z., Petäjä, T., Aalto, P.P., Fu, C.B. and Kulmala, M. (2018). Aerosol optical properties at SORPES in Nanjing, east China. Atmos. Chem. Phys. 18: 5265-5292, doi: 10.5194/acp-18-5265-2018.

Tegen, I, Koch, D., Lacis, A.A. and Sato M. (2000). Trends in tropospheric aerosol loads and corresponding impact on direct radiative forcing between 1950 and 1990: A model study. J. Geophys. Res. 105: 2697126989, doi: 10.1029/2000JD900280.

Tegen, I. and Schepanski, K. (2009). The global distribution of mineral dust. IOP Conf. Ser 7: 012001, doi: 10.10 88/1755-1307/7/1/012001.

Twomey, S. (1974). Pollution and the planetary albedo. Atmos. Environ. 8: 1251-1256.

Wang, J., Wang, S., Jiang, J., Ding, A., Zheng, M., Zhao, B., Wong, D. C., Zhou, W., Zheng, G., Wang, L., Pleim, J.E. and Hao, J. (2014). Impact of aerosol-meteorology interactions on fine particle pollution during China's severe haze episode in January 2013. Environ. Res. Lett. 9: 094002.

Wang, X.H. and Shi, G.Y. (2002). Effect of cloud and surface albedo on direct sulfate radiative forcing over East Asia. Acta Meteor. Sinica 60: 754-765.

Wu, H., Wang, T., Riemer, N., Chen, P., Li, M. and Li, S. (2017). Urban heat island impacted by fine particles in Nanjing, China. Sci. Rep. 7:11422, doi: 10.1038/s41598017-11705-z.

Xia, X., Li, Z., Holben, B., Wang, P., Eck, T., Chen, H., Cribb, M. and Zhao, Y. (2007). Aerosol optical properties and radiative effects in the Yangtze Delta region of China. J. Geophys. Res. 112: D22S12, doi: 10.1029/2007JD008859. 
Xu, C., Duan, J.Y., Wang, Y.Y., Li, M., Cheng, T.T., Wang, H., Zhu, H.L., Xie, X., Liu, Y.H., Ling, Y., Li, X., Kong, L.D., He, Q.S., Wang, H.L. and Zhang, R.J. (2018). Effects of wintertime polluted aerosol on clouds over the Yangtze River Delta: Case study. Aerosol Air Qual. Res. 18: 1799-1816, doi: 10.4209/aaqr.2017.09.0322.

$\mathrm{Xu}, \mathrm{Q}$. (2001). Abrupt change of the mid-summer climate in central east China by the influence of atmospheric pollution. Atmos. Environ. 35: 5029-5040.

Yang, X., Zhao, C.F., Guo, J.P. and Wang, Y. (2016). Intensification of aerosol pollution associated with its feedback with surface solar radiation and winds in Beijing. J. Geophys. Res. 121: 4093-4099, doi: 10.1002/2015JD024645.

Yang, Y., Russell, L.M., Lou, S.J., Liao, H., Guo, J.P., Liu, Y., Singh, B. and Ghan, S.J. (2017). Dust-wind interactions can intensify aerosol pollution over eastern China. Nat. Commun. 8:15333, doi: 10.1038/ncomms15333.

Zhang, H., Wang, Z., Wang, Z., Liu, Q., Gong, S., Zhang, X., Shen, Z., Lu, P., Wei, X., Che, H. and Li, L. (2012). Simulation of direct radiative forcing of aerosols and their effects on East Asian climate using an interactive AGCM-aerosol coupled system. Clim. Dyn. 38: 16751693, doi: 10.1007/s00382-011-1131-0.

Zhang, R., Li, Q. and Zhang, R. (2014). Meteorological conditions for the persistent severe fog and haze event over eastern China in January 2013. Sci. China Earth Sci. 57: 26-35.

Zhang, Y.L., Qin, B.Q. and Chen, W.M. (2004). Analysis of 40-year records of solar radiation data in Shanghai, Nanjing and Hangzhou in eastern China. Theor. Appl. Climatol. 78: 217-227, doi: 10.1007/s00704-003-0030-7.
Zhou, S.Z., Davy, P.K., Wang, X.M., Cohen, J.B., Liang, J.Q., Huang, M.J., Fan, Q., Chen, W.H., Chang, M., Ancelet, T. and Trompetter, W.J. (2016). High timeresolved elemental components in fine and coarse particles in the Pearl River Delta region of Southern China: Dynamic variations and effects of meteorology. Sci. Total Environ. 572: 634-648, doi: 10.1016/j.scitotenv. 2016.05.194.

Zhuang, B.L., Wang, T.J., Li, S., Liu, J., Talbot, R., Mao, H.T., Yang, X.Q., Fu, C.B., Yin, C.Q., Zhu, J.L., Che, H.Z. and Zhang, X.Y. (2014). Optical properties and radiative forcing of urban aerosols in Nanjing, China. Atmos. Environ. 83: 43-52, doi: 10.1016/j.atmosenv.2013. 10.052 .

Zhuang, B.L., Wang, T.J., Liu, J., Li, S., Xie, M., Han, Y., Chen, P.L., Hu, Q.D., Yang, X.Q., Fu, C.B. and Zhu, J.L. (2017). The surface aerosol optical properties in the urban area of Nanjing, west Yangtze River Delta, China. Atmos. Chem. Phys. 17: 1143-1160, doi: 10.5194/acp17-1143-2017.

Zhuang, B.L., Wang, T.J., Liu, J., Che, H.Z., Han, Y., Fu, Y., Li, S., Xie, M., Li, M.M., Chen, P.L., Chen, H.M, Yang, X.Q. and Sun, J.N. (2018). The optical properties, physical properties and direct radiative forcing of urban columnar aerosols in the Yangtze River Delta, China. Atmos. Chem. Phys. 18: 1419-1436, doi: 10.5194/acp18-1419-2018.

Received for review, July 28, 2018 Revised, November 7, 2018 Accepted, March 12, 2019 